This document was prepared in conjunction with work accomplished under Contract No. DE-AC09-96SR18500 with the U.S. Department of Energy.

This work was prepared under an agreement with and funded by the U.S. Government. Neither the U. S. Government or its employees, nor any of its contractors, subcontractors or their employees, makes any express or implied: 1 . warranty or assumes any legal liability for the accuracy, completeness, or for the use or results of such use of any information, product, or process disclosed; or 2 . representation that such use or results of such use would not infringe privately owned rights; or 3 . endorsement or recommendation of any specifically identified commercial product, process, or service. Any views and opinions of authors expressed in this work do not necessarily state or reflect those of the United States Government, or its contractors, or subcontractors. 
WSRC-STI-2007-00143

\title{
JOHNSON-MATTHEY DIFFUSER CHARACTERIZATION TESTING
}

\author{
P. J. Foster ${ }^{1}$, J. E. Klein ${ }^{2}$, H. T. Sessions ${ }^{2}$, and G. A. Morgan ${ }^{2}$ \\ ${ }^{1}$ Washington Savannah River Company: Aiken, SC 29808 \\ ${ }^{2}$ Savannah River National Laboratory: Aiken, SC 29808, james.klein@srs.gov
}

\begin{abstract}
A diffuser/permeator commercially fabricated by Johnson-Matthey was purchased for characterization testing at the Savannah River National Laboratory (SRNL). A test system was fabricated to not only feed and bleed flows and pressures, but also permeate pressure for flows up to 20 SLPM. xxxxx
\end{abstract}

\section{INTRODUCTION}

The Savannah River Site (SRS) Tritium Facilities utilize diffusers/permeators as part of tritium processing operations. Diffusers constructed of palladium-silver $(\mathrm{Pd} / \mathrm{Ag})$ alloy tubing wound into coils have been used for many years at SRS to separate hydrogen isotopes from other gases. ${ }^{1}$

Many times a diffuser is installed in tritium process operations without its performance characteristics fully understood or measured. To this end, a diffuser constructed by a commercial vendor, Johnson-Matthey, Inc. (West Chester, PA USA) was obtained for characterization testing. The diffuser is pictured on the vendor's Gas Purification Technology web page as a "Tritium Purifier". It is desired to determine the full operating limits of this purifier for use in the SRS Tritium Facilities.

\section{BACKGROUND}

Numerous designs of $\mathrm{Pd} / \mathrm{Ag}$ diffusers/permeators have been used at SRS for tritium process operations. ${ }^{1,2}$ $\mathrm{Pd} / \mathrm{Ag}$ diffusers by themselves or combined with catalyst materials in different configurations (e.g. PERMCAT) are key unit operations for fusion reactor plasma exhaust clean-up systems ${ }^{3}$ to remove hydrogen isotopes $\left(\mathrm{Q}_{2}\right)$ from various tritium process streams.

Testing of the diffuser will not only look at its ultimate permeation performance as a function of gas composition and flow rate, but also quantify the diffuser in terms of diffuser theory, diffusion proportional to the difference between the square-root of pressure on both sides of the $\mathrm{Pd} / \mathrm{Ag}$ membrane. This quantification will be useful when diffuser performance appears to have changed and the changes need to be quantified.

This paper presents preliminary cold (i.e. nonradioactive) permeation test results for the described Johnson-Matthey diffuser.

\section{EXPERIMENTAL}

A flow test manifold was assembled for diffuser testing. Diffuser tests were conducted in an "inside-out" manner where the feed mixture was supplied to the inlet of an open-ended $\mathrm{Pd} / \mathrm{Ag}$ coil and the hydrogen would permeate into the surrounding shell space of the diffuser (the permeate or "pure" stream).

Figure 1 shows an X-ray of a Johnson-Matthey diffuser. The heater well can be seen in the center of the diffuser, surrounded by the five $\mathrm{Pd} / \mathrm{Ag}$ coils.

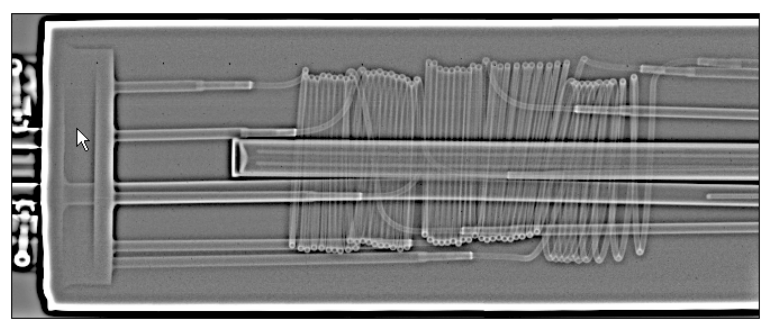

Figure 1. X-ray of diffuser.

Helium, hydrogen, and nitrogen gases were supplied to the diffuser feed tube by mass flow controllers (MFCs). The raffinate, or bleed, tube was connected to a backpressure control valve followed by a vacuum pump. The diffuser shell was evacuated by a Normetex scroll pump backed by a MB-601 Metal Bellows pump with the two heads connected in series. The permeate could go directly to the vacuum pumps or to a back-pressure control valve. The exhaust from the MB-601 was directed to mass flow 
meters for direct measurement of the permeate flow. By knowing the feed rate, the feed composition, and the permeate flow, the bleed/raffinate composition and flow rate could be calculated.

The diffuser had an 1800 watt, central heater cartridge fitted with dual-element Type-K thermocouples (TCs). A thermowell in the shell space of the diffuser also contained a dual-element TC. Of the four available TCs, one channel of a dual TC was used for temperature control and the other for data acquisition while the other dual TC had one channel for over-temperature control and the other channel for data acquisition.

The initial tests were performed using a variac, which supplied constant power to the diffuser heater. The shell temperature was maintained at approximately $400{ }^{\circ} \mathrm{C}$. Under this form of control, various feed gas compositions as well as flow rates were tested at a nominal pressure of 800 torr on the tube side while the shell side was evacuated. Feed compositions ranged from $50 \% \mathrm{H}_{2}$ in $\mathrm{N}_{2}$ to $96 \% \mathrm{H}_{2}$ in $\mathrm{N}_{2}$, as well as $75 \% \mathrm{H}_{2}$ in He. Total feed flow rates ranged from 100 standard cubic centimeters per minute $(\mathrm{sccm})$ to $14,000 \mathrm{sccm}$.

The second method of control involved monitoring the shell temperature and using this to control power to the heater. This method allowed the shell temperature to maintain a constant $400{ }^{\circ} \mathrm{C}$ throughout the testing. A $75 \%$ $\mathrm{H}_{2}$ in $\mathrm{N}_{2}$ feed mix was tested under this method of control and compared to the first method results. Other tests performed using this second method of control involved feeding a $75 \% \mathrm{H}_{2}$ in $\mathrm{N}_{2}$ mix to the diffuser at a flow rate of $10,000 \mathrm{sccm}$ while varying tube pressure. This provided information about the permeation rate as a function of pressure difference between the tube and shell.

\section{RESULTS}

Four primary results obtained from the experiments are described here: effect of composition on breakthrough at $400{ }^{\circ} \mathrm{C}$, effect of inert gas type on breakthrough at 400 ${ }^{\circ} \mathrm{C}$, comparison of variac to temperature control, and permeation characteristic as a function of pressure difference between the tube and shell.

Figure 2 shows the flow rate of the bleed vs the total flow rate of the feed to the diffuser. The temperature for each test (under variac control) was initially $400{ }^{\circ} \mathrm{C}$. The four lines in the plot correspond to various feed compositions of $\mathrm{H}_{2}$ and $\mathrm{N}_{2}\left(50 \%, 75 \%\right.$, and $96 \% \mathrm{H}_{2}$, balance $\mathrm{N}_{2}$ ).

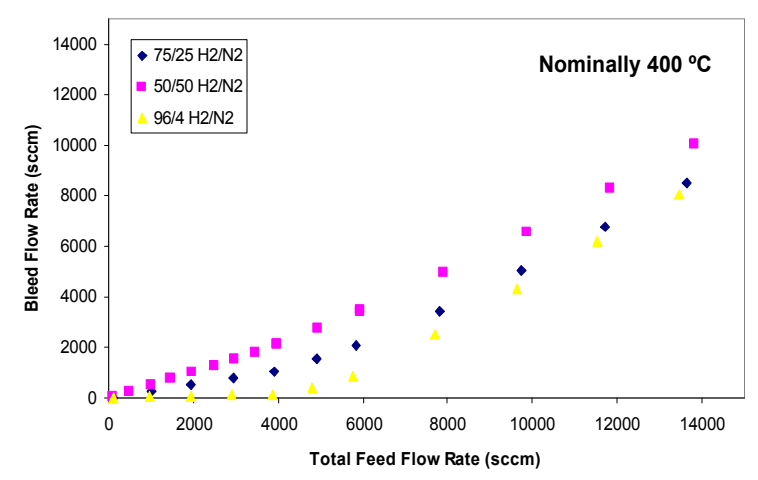

Figure 2. Effect of composition on permeation.

Figure 3 shows just the low flow region of the same plot.

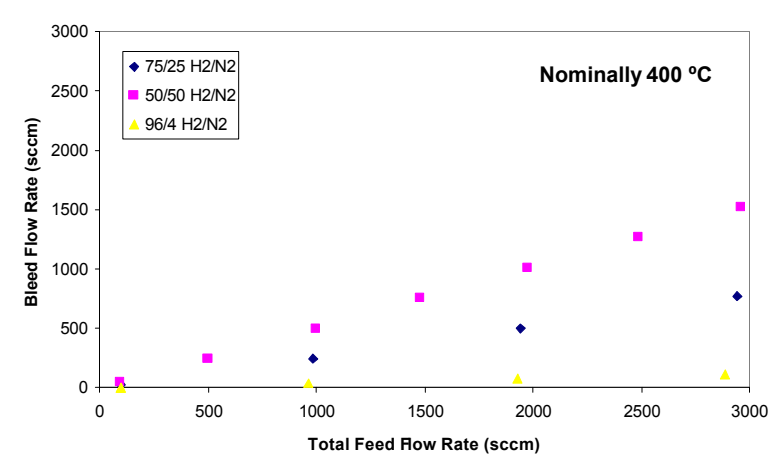

Figure 3. Effect of composition on permeation, low flow region.

The next figure shows the difference between the inert gas used and its effect on the permeation. Both cases consist of a feed composition of $75 \% \mathrm{H}_{2}$, but one uses $\mathrm{N}_{2}$ for the other $25 \%$, and the other uses $\mathrm{He}$.

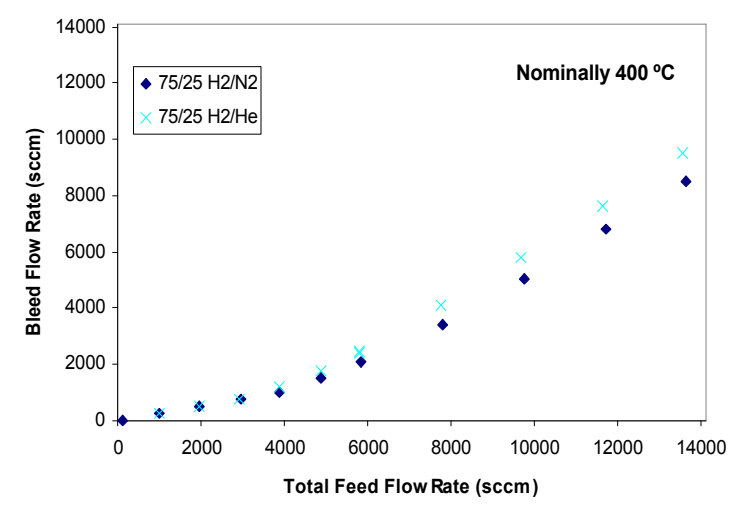

Figure 4. Effect of inert gas type on permeation. 
Figure 5 shows the effect of using a variac to control heater output (and therefore shell temperature) as opposed to using temperature control. In the case of variac control, the shell temperature increased as feed flow rate increased, due to $\mathrm{H}_{2}$ permeating to the shell space and increasing heat transfer from the heater to the shell. However, it only increased to a certain point, beyond which, as feed flow rate increased, shell temperature decreased. The maximum temperature reached in all cases was approximately $420^{\circ} \mathrm{C}$, while the lowest was $386^{\circ} \mathrm{C}$.

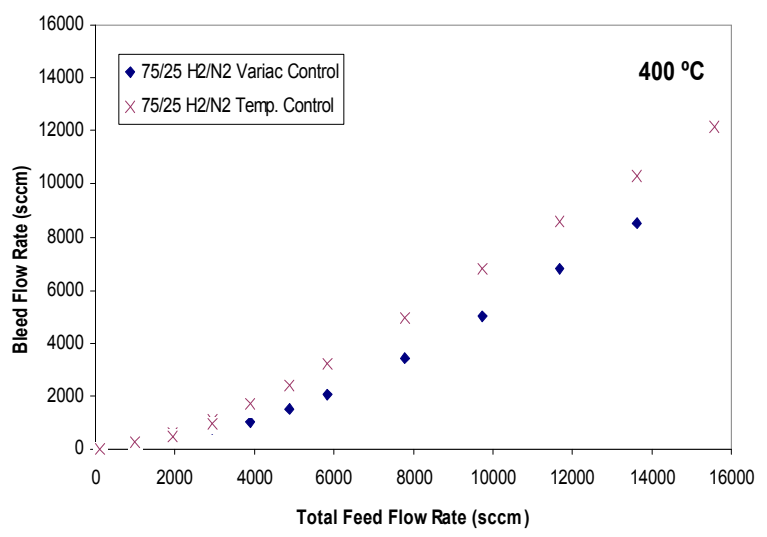

Figure 5. Variac vs. temperature control.

In Figure X, the permeation flow rate is plotted as a function of the difference between the square root of the partial pressure of $\mathrm{H}_{2}$ in the feed and the permeate. As can be seen in the figure, the relationship is linear.

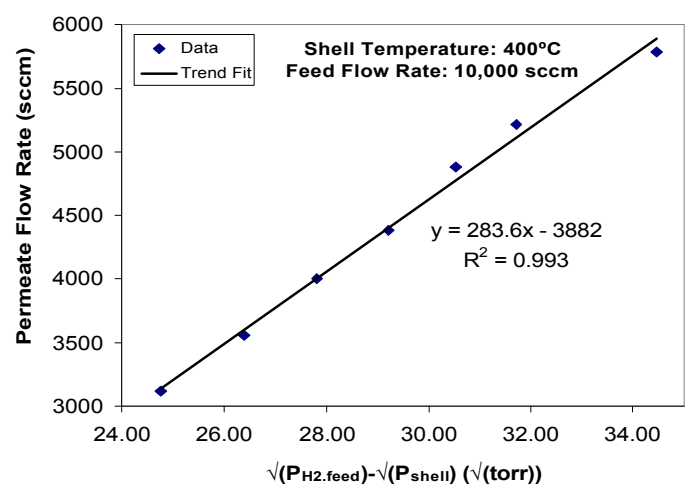

Figure 6. Permeation as a function of pressure difference.
Some distinct features of Figure 2 are that there are two linear lines of differing slopes connected by a transition region. The slope at the lower flow rates indicates that essentially all of the $\mathrm{H}_{2}$ fed to the diffuser permeates into the shell side. At some point, $\mathrm{H}_{2}$ begins to flow the length of the tube without permeating - this is represented by where the curve begins to deviate from the first linear portion. At flow rates above this transition, or breakthrough region, the $\mathrm{H}_{2}$ never completely permeates into the shell, and the amount that exits with the bleed is proportional to the total flow rate of the feed gas, represented by the second linear portion on the plot. In all cases, breakthrough generally occurred in the feed flow range of 3,000 to $6,000 \mathrm{sccm}$.

The effect of feed gas composition on $\mathrm{H}_{2}$ permeation can be seen in Figure 3. As expected, in the initial region where all $\mathrm{H}_{2}$ permeates into the shell space, the slope decreased as partial pressure of $\mathrm{H}_{2}$ in the feed increased. This reflects the smaller amount of inert gas passing through the diffuser without permeating. Once breakthrough occurs, the slopes, which are much more similar than in the initial region, increase in all cases. Although the increase is most significant in the case with the highest $\mathrm{H}_{2}$ partial pressure in the feed, the absolute permeation rate is still greater in this case. (Note: these tests were performed under variac control.)

Figure 4 shows the difference between the type of inert gas used in the experiment. Initially, it appears that in the region prior to breakthrough, there is no difference between the case using $\mathrm{N}_{2}$ and that using $\mathrm{He}$, but once breakthrough occurs, the He reduced $\mathrm{H}_{2}$ permeation. However, in the case where He was used, the average tube pressure was much less than the tube pressure during the case using $\mathrm{N}_{2}$ (approximately 100 torr less at the largest flow rate). A lower pressure in the tube reduces the permeation of $\mathrm{H}_{2}$, so the true effect of using $\mathrm{He}$ rather than $\mathrm{N}_{2}$ is masked by the difference of pressure between the two cases.

The primary difference between using a variac with constant power output to the heater compared with using the shell temperature to control the heater was that using temperature control allowed the shell temperature to be maintained at $400{ }^{\circ} \mathrm{C}$. Under variac control, the power to the heater was constant and therefore unable to correct for changing conditions in the diffuser. For example, as $\mathrm{H}_{2}$ permeated the tube at lower flow rates, the temperature of the shell increased with increasing permeate flow as energy was transferred more readily from the heater to the shell space by the $\mathrm{H}_{2}$ gas. Once the flow rate of gas through the diffuser reached a certain point, the temperature decreased with increasing flow rate. The highest temperature reached in any of the cases was $20^{\circ} \mathrm{C}$ while the lowest temperature reached was $386^{\circ} \mathrm{C}$. Under

\section{DISCUSSION}


temperature control, the shell temperature quickly returned to $400{ }^{\circ} \mathrm{C}$ whenever there was a perturbation in any process parameter.

Figure 5 compares the two cases. In the region before breakthrough occurred there is no difference between the cases - all $\mathrm{H}_{2}$ fed to the diffuser permeated to the shell. Once breakthrough occurred, the permeation of $\mathrm{H}_{2}$ in the variac case deviated from the permeation rate in the temperature controlled case as temperature increased until a steady offset of about 2,000 sccm was reached.

The final result relates the permeate flow rate to the difference in partial pressure of $\mathrm{H}_{2}$ in the feed and $\mathrm{H}_{2}$ pressure in the shell. This test was performed under temperature control with a feed composed of $75 \% \mathrm{H}_{2}$ and $25 \% \mathrm{~N}_{2}$, flowing at $10,000 \mathrm{sccm}$. Average tube pressures ranged from approximately 1,050 torr to about 2,200 torr. At these particular conditions, the relationship between the permeate flow rate and the difference between the square root of the partial pressure of $\mathrm{H}_{2}$ in the feed and the shell is linear.

A number of difficulties in the experiments are noted below. Some of the difficulties in the experiments related to the method of temperature control as well as pressure control. The majority of the tests were performed using a variac to control the temperature. As noted, the temperature did not remain constant during these tests, although it was within $\pm 20^{\circ} \mathrm{C}$ of $400{ }^{\circ} \mathrm{C}$.

In addition, it can be noted in Figure 1 that the thermowell used to measure the shell temperature is located near the end of the diffuser, rather than near the tubes. The experiments assume that the shell temperature reading is the temperature of the tubes in the diffuser. How close the tube temperature is to the measured temperature in the region of the thermowell is unknown.

The regulator used to control pressure in the tube also caused some of the true effects of other variables to be masked. The experiments were generally intended to be measured with a tube pressure of approximately 800 torr. However, as flow rate through the tube increased so did the pressure in the tube due to reaching the capacity of the regulator.

A final difficulty in the experiments involved waiting for steady state. During variac control, the shell temperature continually drifted, although very slightly. This was believed to affect the permeate flow rate as well as permeate pressure. However, this same trend was noted in the cases using temperature control, where shell temperature was constant.

\section{CONCLUSIONS}

The following conclusions can be drawn from the experiments: diffuser temperature significantly affects $\mathrm{H}_{2}$ permeation; the type of inert gas used with the $\mathrm{H}_{2}$ affects pressure as well as permeation; raffinate flow rate is proportional to the amount of feed before and after breakthrough; breakthrough occurs in all cases in a feed flow rate range of approximately 3,000 to $6,000 \mathrm{sccm}$; and the permeation rate is proportional to the difference of square root of $\mathrm{H}_{2}$ partial pressure in the feed and shell.

\section{ACKNOWLEDGMENTS}

The author would like to thank Jim Klein, Tommy Sessions, Gregg Morgan, and Jody Dye for their support of this work. This paper was prepared in connection with work done under Contract No. DE-AC09-96SR18500 with the U. S. Department of Energy.

\section{REFERENCES}

E. A. Clark, D. A. Dauchess, L. K. Heung, R. L. Rabun, and T. Motyka, "Experience with Palladium Diffusers in Tritium Processing," Fusion Technol., 28, 566 (1995).

[2] J. E. Klein, "Shell Temperatures for a SingleHeater Diffuser," Fusion Sci. \& Technol., 48, 59 (20055).

[3] B. Bornschein, M. Glugla, K. Günther, T. L. Le, K. H. Simon, and S. Welte, "Successful Experimental Verification of the Tokamak Exhaust Processing Concept of ITER with the CAPER Facility", Fusion Sci. \& Technol., 48, 11 (2005). 